\title{
UTILIZAÇÃO DE CARVÃO ATIVADO MODIFICADO COM NANOPARTÍCULAS DE PRATA E COBRE PARA REMOÇÃO DE FLÚOR DA ÁGUA
}

\author{
A. M. FELINI ${ }^{1}$, S. L. BAZANA ${ }^{1}$ e R. BERGAMASCO ${ }^{1}$ \\ ${ }^{1}$ Universidade Estadual de Maringá, Departamento de Engenharia Química \\ E-mail para contato: feliniangela@gmail.com
}

\begin{abstract}
RESUMO - Neste trabalho buscou-se uma tecnologia para a produção e aplicação de carvão ativado modificado com nanopartículas de prata e cobre com o objetivo de aumentar a remoção de flúor. $O$ carvão ativado impregnado com metais foi produzido em um sistema piloto por excesso de solvente, seguido pela impregnação à vácuo. Os filtros gravitacionais contendo o meio poroso modificado foram avaliados em relação à eficiência na remoção de flúor. As amostras de carvão ativado modificadas produzidas foram caracterizadas texturalmente pelas medidas da área superficial especifica e de porosidade (SBET, volume e diâmetro de poros) e analise morfológica por microscopia eletrônica de varredura (MEV) e microscopia eletrônica de transmissão (MET). Em relação aos critérios de desempenho dos filtros com os meios porosos produzidos, os parâmetros analisados devem estar de acordo com os limites estabelecidos pela Portaria 2914/2011.
\end{abstract}

\section{INTRODUÇÃO}

Alguns compostos podem alterar a qualidade da água que é destinada para o consumo humano e segundo a Organização Mundial da Saúde (OMS), um dos compostos que contaminam a água é o flúor, que em concentrações elevadas, acima de $1,5 \mathrm{mg} \mathrm{L}^{-1}$, se torna prejudicial para a saúde humana. A contaminação das águas subterrâneas por flúor pode ocorrer por fatores naturais e ainda pode ser gerada pela atividade em indústrias de alumínio, onde é utilizado como fundente, e também no setor nuclear, onde todo o ciclo de enriquecimento de urânio é efetuado através do uso de compostos fluorados (Alvarinho e Martinelli, 2000).

Durante o período de formação dos dentes, se for ingerido flúor em excesso, pode ocorrer uma intoxicação crônica e originar a fluorose dentária. Esta patologia se manifesta por meio de manchas esbranquiçadas e amarronzadas na superfície do esmalte dentário ou, até mesmo, por perdas em sua estrutura (Cardoso et al., 2001).

Alguns processos para a remoção de flúor, como eletrocoagulação, eletroflotação e processos de separação por membranas tem custo e complexidade elevados (Chen et al., 2011; Deng et al., 2011). Uma técnica mais econômica e simples para remoção deste contaminante é a utilização de carvão ativado como adsorvente no tratamento da água, visto que este é um excelente adsorvente, com estrutura porosa altamente desenvolvida e com uma 
grande capacidade para remover sabor e o odor da água, além de eliminar contaminantes orgânicos e inorgânicos (Hamdaoui e Naffrechow, 2007; Cheng et al., 2005).

Por ter área superficial elevada em relação ao volume, o carvão ativado granular é um bom meio adsorvente. Um grama de um carbono ativado comercial típico terá uma área de superfície equivalente a $1000 \mathrm{~m}^{2}$, o que permite a acumulação de um grande número de moléculas contaminantes. A capacidade específica de um carvão ativado granular para adsorver compostos orgânicos está relacionado com a atração molecular na superfície, a área total da superfície disponível por unidade de peso de carbono, e a concentração de contaminantes na corrente de águas residuais (Chatuverdi e Dave, 2012).

A impregnação em meios porosos tem o objetivo de melhorar as propriedades já existentes e promover a interação entre o carvão ativado e o agente de impregnação para aumentar a capacidade de adsorção. Tem também a função de impulsionar a capacidade do carvão ativado como transportador poroso inerte. Em algumas aplicações, os agentes de impregnação estão presentes nas formas de hidróxidos, carbonatos, cromatos ou nitratos, onde o carvão ativado impregnado deve ser submetido a um tratamento térmico em temperaturas elevadas $\left(150-200{ }^{\circ} \mathrm{C}\right.$ ) para decompor os metais (Yin et al., 2007).

\section{OBJETIVOS}

O presente trabalho tem como objetivo modificar o carvão ativado granular a partir da impregnação com os metais prata e cobre em um reator de escala piloto e avaliar a sua potencialidade na remoção de flúor da água.

\section{METODOLOGIA}

Utilizou-se o método de impregnação a vácuo com soluções aquosas de $\mathrm{AgNO}_{3}$ e $\mathrm{Cu}_{2} \mathrm{SO}_{4} \cdot 5 . \mathrm{H}_{2} \mathrm{O}$ em um reator em unidade piloto, onde a amostra de carvão ativado de babaçu (FILTRON, Brasil) e as soluções aquosas metálicas foram misturadas e mantidas a $100^{\circ} \mathrm{C}$ por 30 minutos. Posteriormente as amostras foram secas em estufa e submetidas a um tratamento térmico em forno mufla a $350^{\circ} \mathrm{C}$ por 5 horas.

Antes e depois do processo de impregnação com metais, foi realizada a caracterização textural das amostras de carvão em um sistema de sorção de gases pela adsorção/dessorção de nitrogênio $\left(\mathrm{N}_{2}\right)$. A caracterização morfológica foi feita através de microscopia eletrônica de transmissão (MET) e microscopia eletrônica de varredura (MEV) para análise da microestrutura superficial das amostras de carvão ativado.

Para a avaliação da capacidade de adsorção do flúor foi feita uma solução de $50 \mathrm{~mL}$ de flúor com concentração inicial de $6 \mathrm{mg}$. $\mathrm{L}^{-1}$ que foi colocada em contato com $0,5 \mathrm{~g}$ do carvão ativado a ser testado. No $\mathrm{pH}$ da solução (próximo a 7), as amostras foram deixadas em incubadora refrigerada com agitação, também conhecida como shaker, sob agitação de 130 rpm durante 6 horas e temperatura de $30{ }^{\circ} \mathrm{C}$. Após esse período, a amostra foi retirada e analisada. $\mathrm{O}$ teste foi realizado em duplicata.

\section{RESULTADOS E DISCUSSÕES}


Os resultados das análises de fisissorção de nitrogênio mostraram a predominância da área microporosa do carvão estudado, conforme mostrado na Tabela 1. A impregnação com metais no carvão aumentou a área de mesoporos Smeso, o que pode ser devido à impregnação a vácuo. Segundo Yang e Qiu (2010), o efeito da pressão no sistema contribui para o desenvolvimento da área superficial e dos poros do carvão ativado.

O carvão que passou por modificações sofreu redução do volume total do poro, $\mathrm{Vp}$, o que pode ter ocorrido devido à obstrução parcial dos poros do carvão original diminuindo assim seu volume e área superficial. Isso é resultado da interação entre os metais adicionados e o carvão ativado, e também pela formação de um grande número de complexos oxigenados superficiais (Goscianska et al., 2012).

Tabela 1 - Parâmetros texturais obtidos das análises de fisissorção de nitrogênio dos materiais produzidos

\begin{tabular}{|c|c|c|c|c|c|c|c|}
\hline \multirow{2}{*}{ Amostra } & $\mathrm{S}_{\text {micro }}$ & \multicolumn{3}{|c|}{ Microporos } & \multicolumn{3}{c|}{ Mesoporos } \\
\cline { 3 - 8 } & $\left(\mathrm{mg}^{2} \cdot \mathrm{g}^{-1}\right)$ & $\begin{array}{c}\mathrm{S}_{\text {micro }} \\
\left(\mathrm{mg}^{2} \cdot \mathrm{g}^{-1}\right)\end{array}$ & $\begin{array}{c}\mathrm{V}_{\text {micro }} \\
\left(\mathrm{cm}^{3} \cdot \mathrm{g}^{-1}\right)\end{array}$ & $\begin{array}{c}\mathrm{d}_{\text {micro }} \\
(\mathrm{A})\end{array}$ & $\begin{array}{c}\mathrm{S}_{\text {meso }} \\
\left(\mathrm{mg}^{2} \cdot \mathrm{g}^{-1}\right)\end{array}$ & $\begin{array}{c}\mathrm{V}_{\text {meso }} \\
\left(\mathrm{cm}^{3} \cdot \mathrm{g}^{-1}\right)\end{array}$ & $\mathrm{D}_{\text {meso }}(\mathrm{A}$ \\
\hline C puro & 660,81 & 560,12 & 0,29 & $<10,22$ & 33,52 & 0,027 & 34,15 \\
\hline C Impregnado & 631,00 & 528,16 & 0,28 & $<10,30$ & 42,76 & 0,024 & 35,09 \\
\hline
\end{tabular}

Na Figura 1 são representadas as isotermas de adsorção e dessorção de N2 a 77 K do carvão ativado impregnado com metais e do carvão ativado sem impregnação, onde as curvas são descritas pelo volume (V) de gás adsorvido ou dessorvido em função da pressão relativa $\left(\mathrm{P} / \mathrm{P}_{0}\right)$.

Figura 1 - Isotermas de adsorção e dessorção

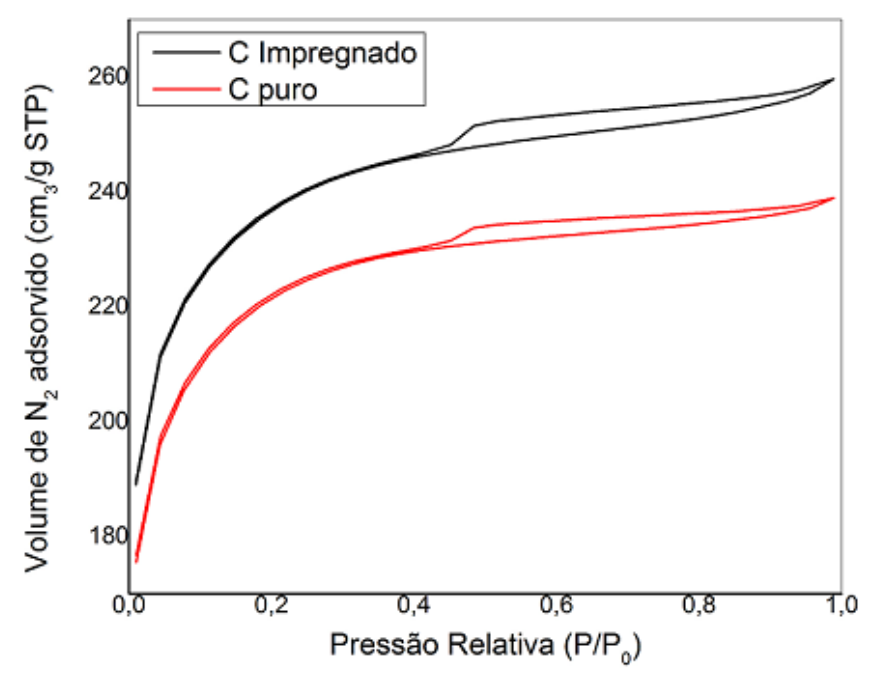

De acordo com a classificação BET, o tipo de curva indica que as amostras de carvão analisadas são predominantemente microporosas, pois as isotermas de adsorção apresentam forma aproximadamente horizontal ao eixo $\mathrm{P} / \mathrm{P}_{0}$ (Isoterma Tipo I). Os estudos de Aygün e Duman (2003) tiveram resultados similares de isotermas do Tipo I, com distribuição de microporos em carvão vegetal, característica de isotermas com alta capacidade de adsorção para moléculas de dimensões pequenas, como gases e solventes comuns. 
Além disso observa-se a presença de histerese nas curvas de adsorção-dessorção, indicando a presença de mesoporos. As histereses são do tipo H3, caracterizando sólidos formados por agregados ou aglomerados de partículas, gerando poros tipo fenda com tamanho não uniforme. Este é um processo indistinguível da formação de monocamada. Visto que ocorre o enchimento dos microporos, a adsorção continua na superfície externa por meio do processo de adsorção em multicamada (Leofanti et al., 1998).

Na Figura 2 está representada a caracterização morfológica realizada por meio de microscopia eletrônica de varredura (MEV) nas amostras de carvão antes e depois do processo de impregnação, para análise da microestrutura superficial. Na imagem identifica-se a morfologia porosa do carvão ativado. As pequenas partículas sobre a matriz do carvão modificado com metais provavelmente resultam do processo de impregnação, representando a presença de partículas de prata e cobre.

Figura 2 - Comparação entre carvão puro (esquerda) e impregnado (direita) através de microscopia eletrônica de varredura

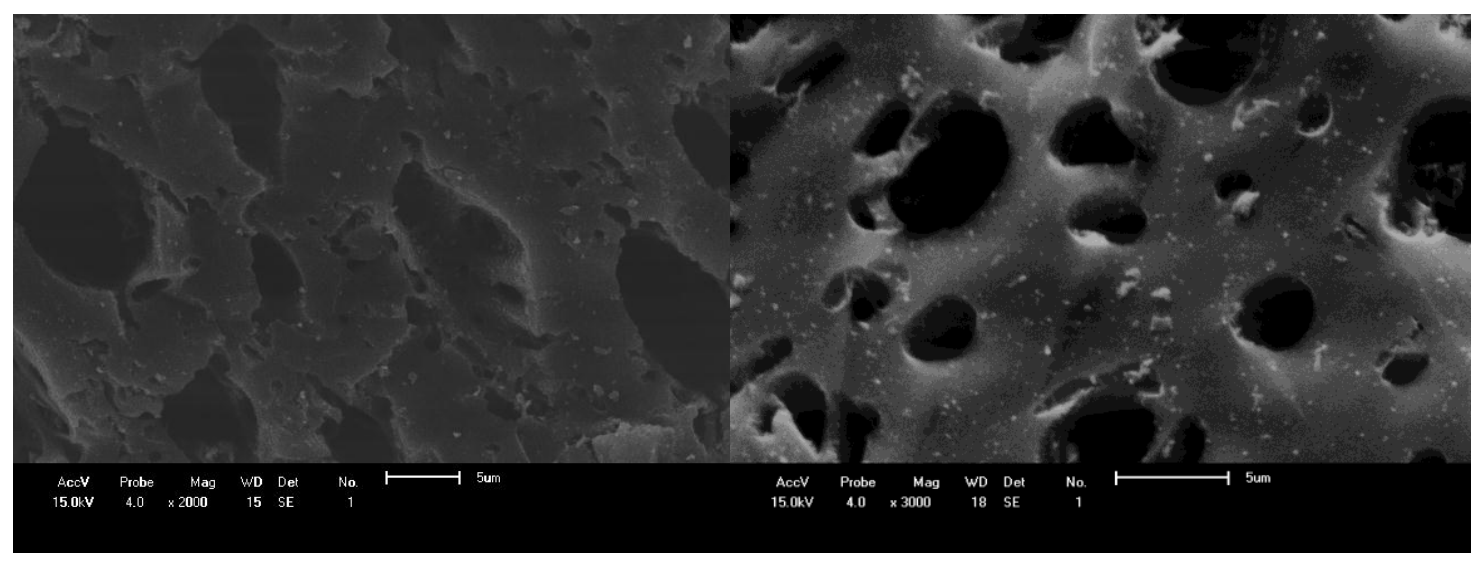

A análise morfológica por Microscopia Eletrônica de Transmissão é representada na Figura 3.

Figura 3 - Comparação entre carvão puro (esquerda) e impregnado (direita) através de microscopia eletrônica de transmissão

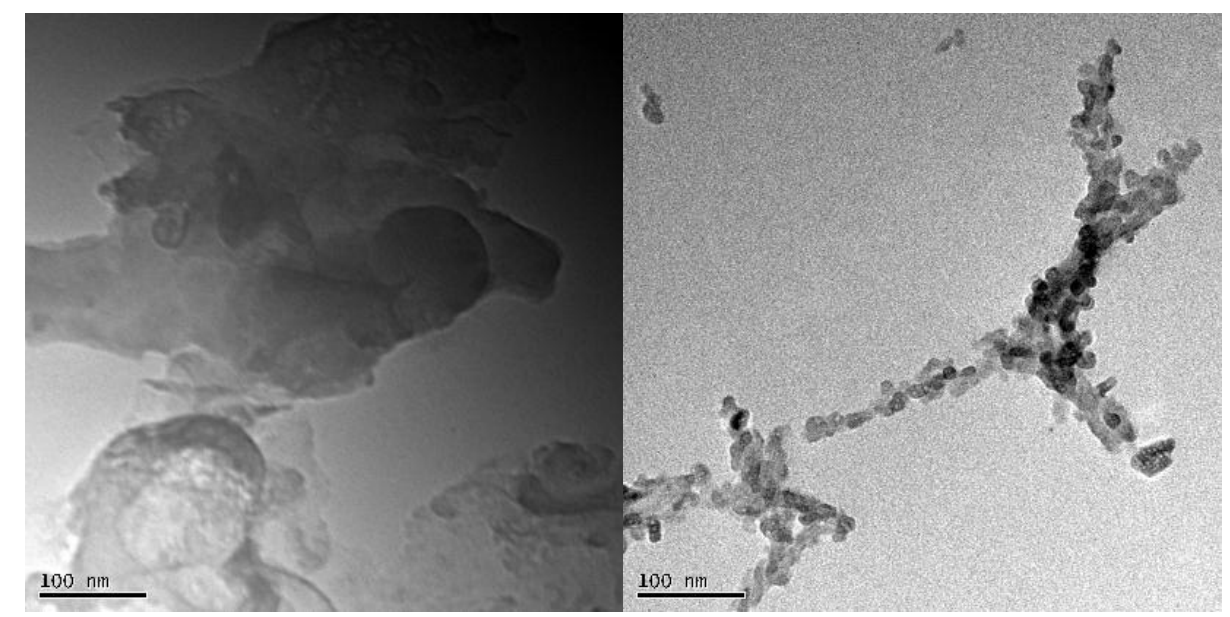


A análise da Figura 3 mostra que em todas as imagens da matriz carbonácea, de tonalidade acinzentada, são identificados aglomerados de forma esférica com coloração mais escura, características de partículas metálicas, neste caso, nanopartículas metálicas e/ou óxidos de $\mathrm{Ag}$ e $\mathrm{Cu}$.

A avaliação da eficiência na remoção de flúor para os carvões puro e modificado é mostrada na Figura 3, onde as amostras foram testadas em pH 3, 7 e 10.

Figura 4 - Avaliação da remoção de flúor para os sistemas de carvão ativado

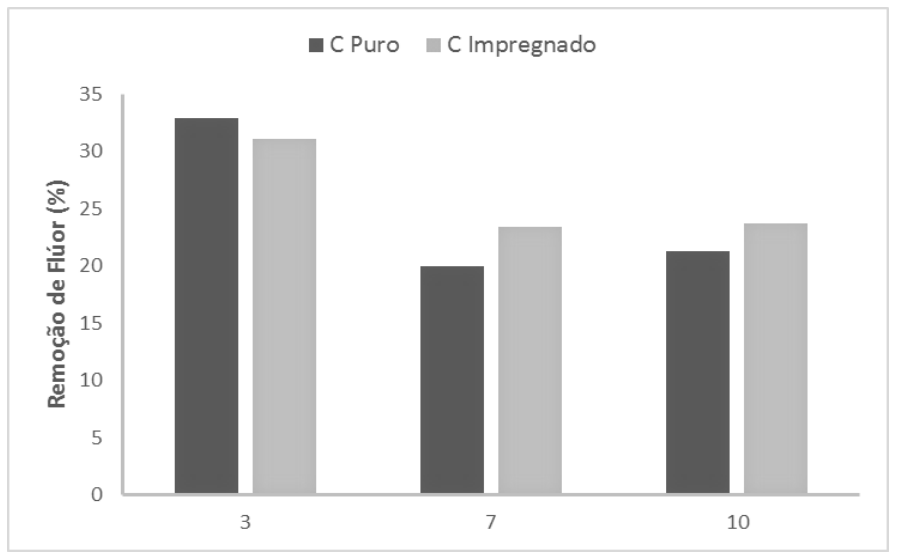

De acordo com os dados obtidos, o melhor desempenho na remoção de flúor para o carvão modificado com metais, em relação ao carvão puro, ocorreu em pH neutro, apresentando $23,5 \%$ de remoção. Os resultados obtidos para as amostras de água em pH 3 e 10 foram muito próximos. A maior capacidade de remoção de flúor de todos os testes foi alcançada em pH 3. Estudos realizados por Silveira et al. (2014), também mostraram os melhores resultados para este valor de $\mathrm{pH}$. No entanto, a remoção foi maior para o carvão puro, mostrando que o processo de impregnação não é vantajoso para este valor de $\mathrm{pH}$. Os testes para os outros valores de $\mathrm{pH}$ mostram que a presença de metas impregnados na superfície do carvão não tiveram influência significativa na remoção de flúor. Em todos os testes, a concentração final do contaminante foi maior que o limite máximo estabelecido pela OMS, que é de $1,5 \mathrm{mg} \mathrm{L}^{-1}$.

\section{CONCLUSÕES}

Conforme os resultados deste trabalho, verificou-se que as alterações com metais nas amostras de carvão ativado aumentaram a área de mesoporos $\left(\mathrm{S}_{\text {meso }}\right)$ e todos os meios apresentaram redução do volume total do poro, Vp. Além disso, as isotermas indicam que os carvões ativados avaliados são predominantemente microporosos.Em relação ao flúor, a remoção obtida não foi muito significativa, alcançando o máximo de remoção de $33 \%$. Ademais, os resultados indicam que a presença de partículas de prata e cobre não interferem significativamente na adsorção deste contaminante.

\section{REFERÊNCIAS}

ALVARINHO, S. B.; MARTINELLI, J. R. The use of alumina to remove fluorine from water and effluents. Cerâmica, São Paulo, v. 46, no. 298, p.104-117, abr./jun. 2000. 
AYGÜN, Y. S.; DUMAN, I. Production of granular activated carbon from fruit stones and nutshells and evaluation of their physical, chemical and adsorption properties. Microporous and Mesoporous Materials, v.66, p. 189-195, 2003.

CARDOSO, L.; MORITA, M.C.; ALVES, J.C.; LICHT, O.A.B. Anomalia hidrogeoquímica e ocorrência de fluorose dentária em Itambaracá-Pr. In: Congresso Brasileiro de Geoquímica, Curitiba, 2001.

CHATURVEDI, S.; DAVE, N, P. Removal of iron for safe drinking water. Desalination v.303, p. $1-1,2012$.

CHEN, N.; ZHANG, Z.; FENG, C.; LI, M.; ZHU, D.; SUGIURA N. Studies on fluoride adsorption of iron impregnated granular ceramics from aqueous solution. Materials Chemistry Physics. v. 125, p. 293-298, 2011.

CHENG, H.; DASTGHEIB, S.A.; KARANFIL, T. Adsorption of dissolved natural organic matter by modified activated carbons. Water Research, v.39, p.2281-2290, 2005.

DENG, S.; Liu, H.; Zhou, W.; Huang, J.; Yu, G.. Mn-Ce oxide as a high-capacity adsorbent for fluoride removal from water. Journal Hazardous Materials, v. 186, p. 1360-1366, 2011.

GOSCIANSKA, J.; NOWAK, I.; NOWICKI, P.; PIETRZAK, R. The influence of silver on the physicochemical and catalytic properties of activated carbons. Chemical Engineering Journal, v. 189-190, p. 422-430, 2012.

HAMDAOUI, O.; NAFFRECHOW, E. Modeling of adsorption isotherms of phenol and chlorofenols onto granular activated carbon. Part I. Two-parameter models and equations allowing determination of thermodynamic parameters, Journal Hazard Materials, v.147, p.381-394, 2007.

LEOFANTI, G.; PADOVAN, M.; TOZZOLA, G.; VENTURELLI, B. 1998. Surface area and pore texture of catalysts. Catalysis Today, 41, 207-219, 1998.

SILVEIRA, C.; MARIN, P.; SHIMABUKU, Q. L.; ARAKAWA, F. S.; BORTOLOZZO, F. G.; CRUZ, N. R.; SANTOS, T. R. T.; BAZANA, S. L.; VIEIRA, A. M. S.; BERGAMASCO, R. Remoção de íons fluoreto de águas para consumo humano pelo processo de adsorção utilizando carvão ativado. In: Congresso Brasileiro de Engenharia Química, Florianópolis, Brasil. 2014.

YANG, J.; QIU, K. Preparation of activated carbons from walnut shells via vacuum chemical activation and their application for methylene blue removal. Chemical Engineering Journal, v.165, p.209-217, 2010.

YIN, C.Y.; AROUA, M.K.; DAUD, W.M.A.W. Review of modifications of activated carbon for enhancing contaminant uptakes from aqueous solutions. Separation and Purification Technology, v.52, p.403-415, 2007. 